Check for updates

Cite this: Chem. Sci., 2019, 10, 10556

¿ All publication charges for this article have been paid for by the Royal Society of Chemistry

Received 27th July 2019

Accepted 19th September 2019

DOI: $10.1039 /$ c9sc03710a

rsc.li/chemical-science

\section{Sustainable ppm level palladium-catalyzed aminations in nanoreactors under mild, aqueous conditions $\uparrow$}

\author{
Yitao Zhang, ${ }^{a}$ Balaram S. Takale, (D) a Fabrice Gallou, (iD b John Reilly ${ }^{\mathrm{c}}$ \\ and Bruce H. Lipshutz (D) *a
}

A $1: 1 \mathrm{Pd}$ : ligand complex, [t-BuXPhos(Pd- $\pi$-cinnamyl)]OTf, has been identified as a highly robust precatalyst for amination reactions leading to diarylamines, where loadings of metal are typically at $1000 \mathrm{ppm} \mathrm{Pd}$, run in water at temperatures between rt and $45^{\circ} \mathrm{C}$. The protocol is exceptionally simple, is readily scaled, and compares very favorably vs. traditional amination conditions. It has also been shown to successfully lead to key intermediates associated with several physiologically active compounds.

\section{Introduction}

Ligated palladium has been and continues to be a privileged catalyst in the realm of organic synthesis. ${ }^{1}$ In particular, the widespread application of Heck, Suzuki-Miyaura, and Negishi coupling reactions earned them the highest appreciation in chemistry. ${ }^{2}$ Palladium-catalyzed aminations have also been pursued enthusiastically in fields ranging from pharmaceuticals and agrochemicals to others in the fine chemical industry. ${ }^{3}$ The versatility and utility of such aminations has also made it among the more reliable methods for construction of $\mathrm{C}-\mathrm{N}$ bonds that are so prevalent in many target molecules. ${ }^{4}$ Since the mid 1990's, extensive ligand design as well as mechanistic investigations have emerged, leading to commonly employed phosphine ligands that tend to be monodentate, bidentate, or dialkylbiarylphosphines. ${ }^{5}$ Development of pre-catalysts that generate active $\operatorname{Pd}(0)$ species in the reaction mixture have been also actively investigated. ${ }^{6}$ Notable examples include $\mathrm{Pd} /$ phosphine ligand complexes, palladacycles, and NHCs, among others. ${ }^{6}$ Several generations of pre-catalysts have been developed, with each system allowing a seemingly broader substrate scope. ${ }^{7}$ Nonetheless, much of the literature suggests that conditions typically used for these aminations are generally harsh, involving high boiling organic solvents (e.g., toluene, dioxane, DMF, etc.) as the reaction medium, oftentimes requiring extended reaction times. ${ }^{3}$ Moreover, catalyst loadings in the $2-10 \mathrm{~mol} \%$ range of Pd are not uncommon, ${ }^{4 e}$ representing a non-sustainable scenario given the endangered status of

${ }^{a}$ Department of Chemistry and Biochemistry, University of California Santa Barbara, Santa Barbara, CA 93106, USA. E-mail: lipshutz@chem.ucsb.edu

${ }^{b}$ Novartis Pharma AG, Basel, Switzerland

${ }^{c}$ Novartis Institutes for BioMedical Research (NIBR), Cambridge, MA, USA

$\dagger$ Electronic supplementary information (ESI) available. See DOI: 10.1039/c9sc03710a platinoids. ${ }^{8}$ Hence, a procedure that is not only general and mild but can also be used under environmentally responsible conditions would be highly desirable, perhaps encouraging further use of this approach to $\mathrm{C}-\mathrm{N}$ bond formation. Towards this goal, we and others have identified ligand scaffolds that complex Pd forming catalysts that mediate such couplings under mild, micellar conditions in water. ${ }^{9}$ However, the crucial reaction parameters involving reduction in the amount of endangered metal required for catalysis to a sustainable level had yet to be achieved; indeed, in addition to high loadings being the norm, even greater amounts of privileged ligands are required. To begin to convert Pd-catalyzed aminations to truly sustainable processes, we have endeavored to develop, and this contribution report on, a general protocol that takes place in water, requires little-to-no investment in energy other than that available between room temperature and $45{ }^{\circ} \mathrm{C}$, and is particularly mindful of the endangered status of palladium. ${ }^{8,10}$

Reducing the loading of a Pd catalyst by 1-2 orders of magnitude requires a significant net increase in reagent activity. Realization of this goal becomes all the more challenging in that high levels of reaction conversion must be realized within reasonable timeframes. Among the many catalysts screened for this study, some of which are shown in Scheme 1, we took special note of reports by Colacot and co-workers describing two new classes of $\pi$-allylpalladium complexes containing biarylphosphine ligands. ${ }^{6 d f} f$

Though mechanistic aspects of these studies were not investigated in aqueous media, in organic solvents it was shown that active "L-Pd(0)" species could be generated from either neutral or cationic ligated frameworks that are both air- and moisture-stable. ${ }^{6 f}$ These preformed monoligated-Pd complexes are particularly appealing as they avoid use of excess ligands which are formally unnecessary for the catalytic cycle, ultimately generate organic waste, and can add cost to the overall process. Moreover, such catalyst precursors help ensure 
(A) sustainable approach to Pd-catalyzed aminations

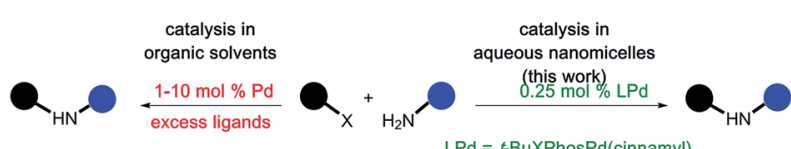

$\mathrm{LPd}=t-\mathrm{BuXPhosPd}($ cinnamyl $)$

(B) model reaction partners, with selected well-defined Pd pre-catalysts screened

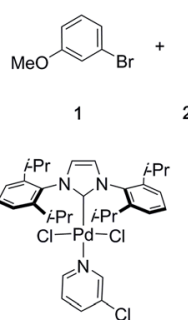

C1

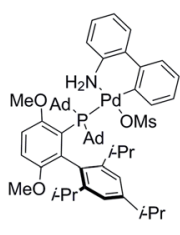

C5

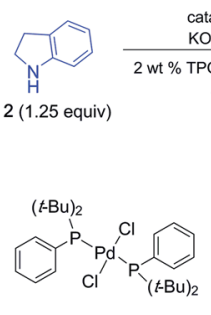

$\mathrm{C} 2$

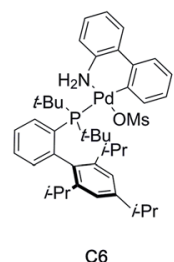

C6
TPGS- $750-\mathrm{M} / \mathrm{H}_{2} \mathrm{O}(0.5 \mathrm{M})$
$45^{\circ} \mathrm{C}, 16 \mathrm{~h}$

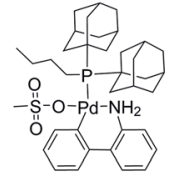

C3

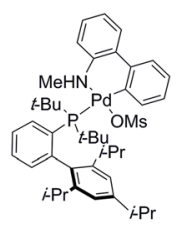

C7

C4

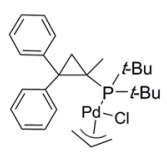

Scheme 1 Defined LPd complexes used at 1000 ppm loading level (see ESI $\dagger$ for the complete list of pre-catalysts screened).

consistent results between batches, which has obvious advantages over in situ preparations both at an early stage of discovery as well as in future applications, especially at scale. ${ }^{11}$

\section{Results and discussion}

A model reaction between 3-bromoanisole (1) and indoline (2) was initially used to screen for catalyst activity, where only $1000 \mathrm{ppm}$ (i.e., $0.10 \mathrm{~mol} \%$ ) of the Pd-containing catalyst was invested. All reactions were run using nanomicelles derived from TPGS-750-M in water between rt and $45{ }^{\circ} \mathrm{C}$. While several pre-catalysts failed to deliver any detectable product, systems featuring a biarylphosphine scaffold proved more active, as noted previously by the Schmitt group. ${ }^{9 e}$ Among $t$-BuXPhosbased complexes, the three cationic species $[t-\mathrm{BuXPhos}(\mathrm{Pd}-\pi-$ allyl)]OTf (C8), [t-BuXPhos(Pd- $\pi$-crotyl)]OTf (C9) and $[t$-BuXPhos(Pd- $\pi$-cinnamyl)]OTf (C10) each led with high efficiency to the desired amination product. The most lipophilic pre-catalyst, C10, afforded the diarylamine 3 in close to quantitative yield. Use of triflate salts was crucial, as the corresponding chlorides were less effective, presumably due to their tendency to form dimeric complexes via bridging chloride ions, species that are apparently catalytically inferior. ${ }^{6 d-f}$

Having identified C10 as the most effective pre-catalyst under micellar conditions at the $1000 \mathrm{ppm}$ level of Pd, we evaluated the scope of this $\mathrm{C}-\mathrm{N}$ coupling chemistry between anilines/aniline-like amines and aryl bromides (Scheme 2). Primary and secondary anilines reacted efficiently between $\mathrm{rt}$ and $45{ }^{\circ} \mathrm{C}$ with aryl bromides bearing electron-donating, -withdrawing, or neutral substituents (products 3-20). A
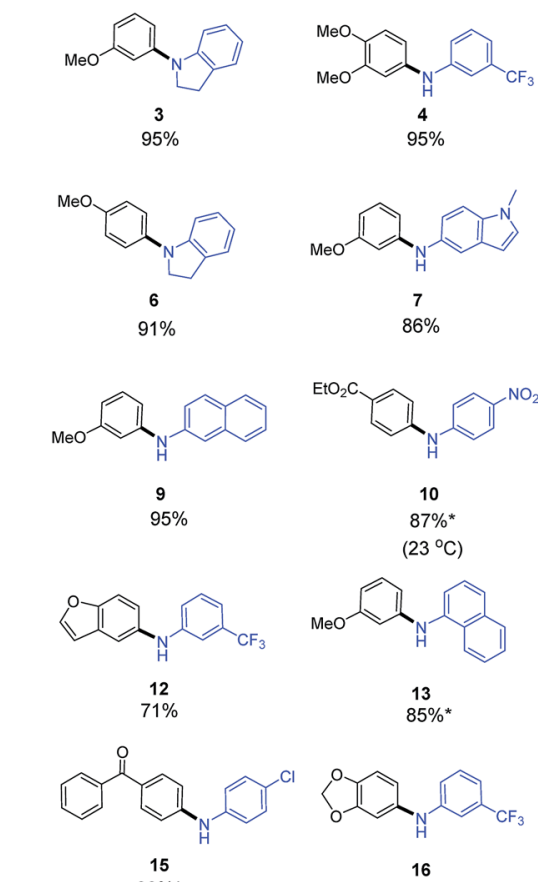

6

$91 \%$
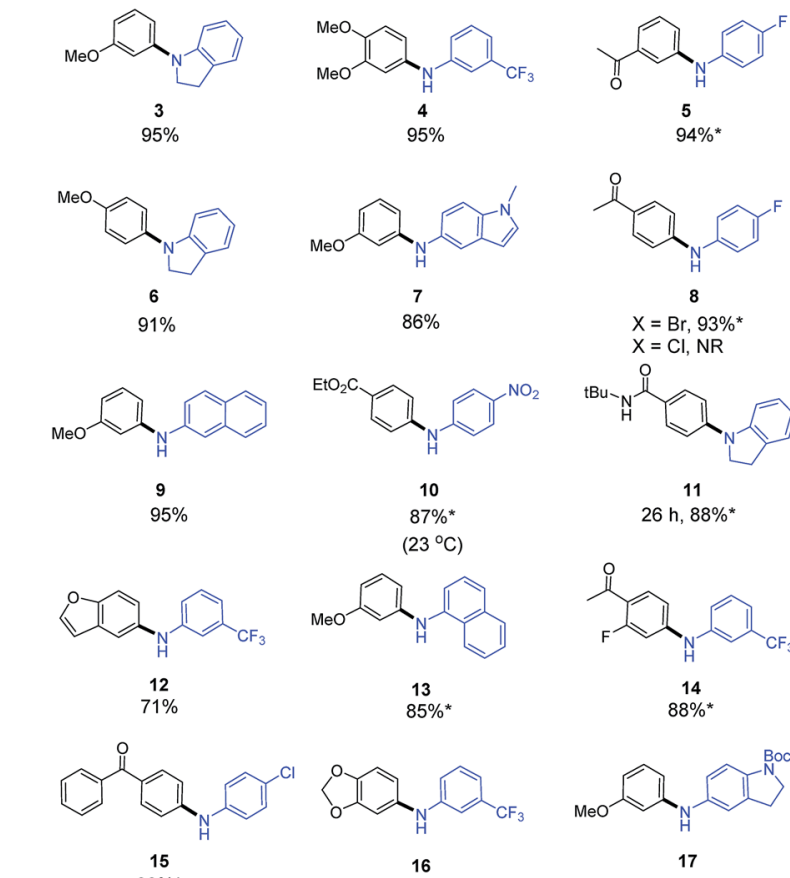

(B)
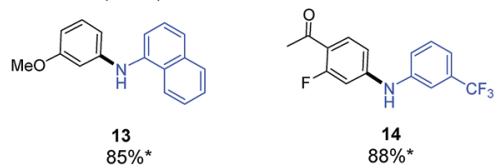

$99 \% *$
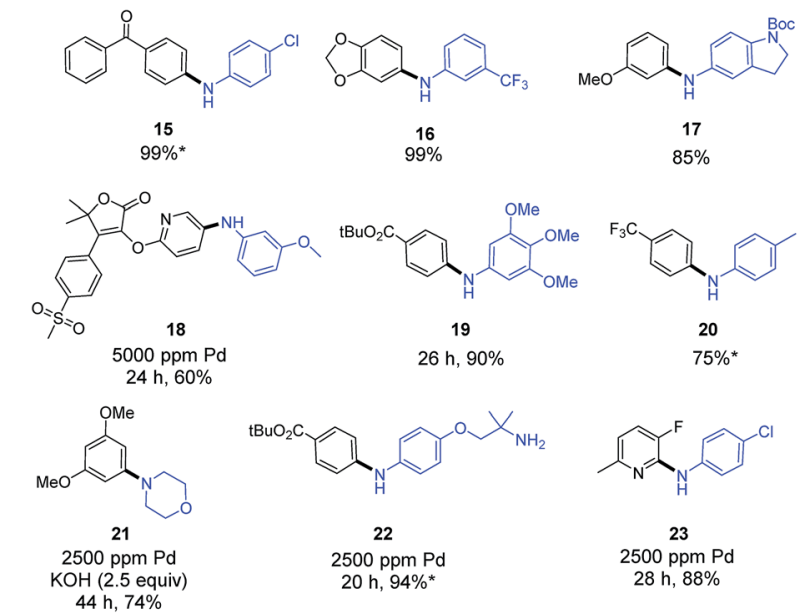

$99 \%$

$85 \%$

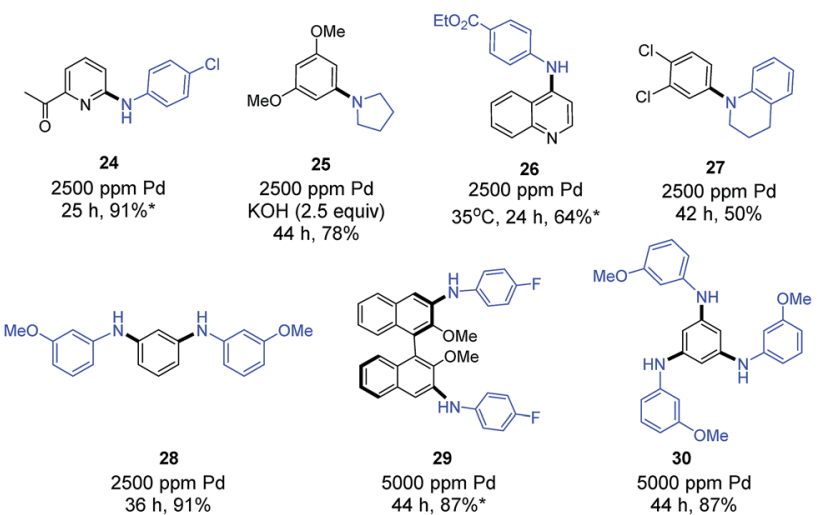

Scheme 2 Representative examples of aminations under sustainable aqueous micellar conditions. Unless otherwise mentioned: $X=B r$, $[\mathrm{LPd}]=1000 \mathrm{ppm}\left[\mathrm{t}-\mathrm{BuXPhosPd}\right.$ (cinnamyl)]OTf, temp $=45^{\circ} \mathrm{C}$, time $=$ $16 \mathrm{~h}$; $\mathrm{KO}-\mathrm{t}$-Bu or $\mathrm{K}_{3} \mathrm{PO}_{4} \cdot \mathrm{H}_{2} \mathrm{O}$ used as inorganic base in $2 \mathrm{wt} \%$ TPGS$750-\mathrm{M}$ at $0.5 \mathrm{M}$ global concentration (see ESI $\uparrow$ for additional details). *Product isolated by simple filtration.

highly functionalized heterocyclic bromide from the Merck Informer Library X3 (ref. 12) also participated to give the desired product 18. ${ }^{13}$ Aryl chlorides were totally inert under these conditions (e.g., 8), and hence, complete selectivity for 
a bromide over chloride is assured based on formation of products 15, 23, 24, and 27. For reactions that proved to be particularly sluggish, an increase in the loading of Pd (from 0.10 to $0.25 \mathrm{~mol} \%$ ) led to the desired $\mathrm{C}-\mathrm{N}$ bonds, as shown for products 21-27. Among these, secondary alkyl amino compounds such as morpholine (to give 21) and pyrrolidine (to give 25) could be used, though an excess of inorganic base was needed to achieve reasonable levels of conversion in both cases. Multiple $\mathrm{C}-\mathrm{N}$ cross-couplings in 1-pot could be effected leading to both $C_{2^{-}}, C_{3}$-symmetric, and axially chiral amination products 28-30, each in high overall yield. The latter two products required an increase to $5000 \mathrm{ppm}$ of $\mathrm{Pd}$ catalyst, although multiple $\mathrm{C}-\mathrm{N}$ bonds were made in each case.

Procedurally, this new protocol involves a very straightforward benchtop setup, requires no glovebox operations, and the catalysts used (e.g., $\mathbf{C 8}$ and $\mathbf{C 1 0})$ are easily prepared and stored. ${ }^{6 f}$ Moreover, in many of the cases shown in Scheme 2, the solid products formed precipitate out of the aqueous medium necessitating only filtration, thereby avoiding any formal workup. Subsequent trituration leads to pure product without reliance on column chromatography, further minimizing both organic solvent and aqueous waste streams.

As aniline coupling partners are susceptible to oxidation, they are best purified prior to use. On the other hand, the corresponding nitro group-containing derivatives, as precursors,
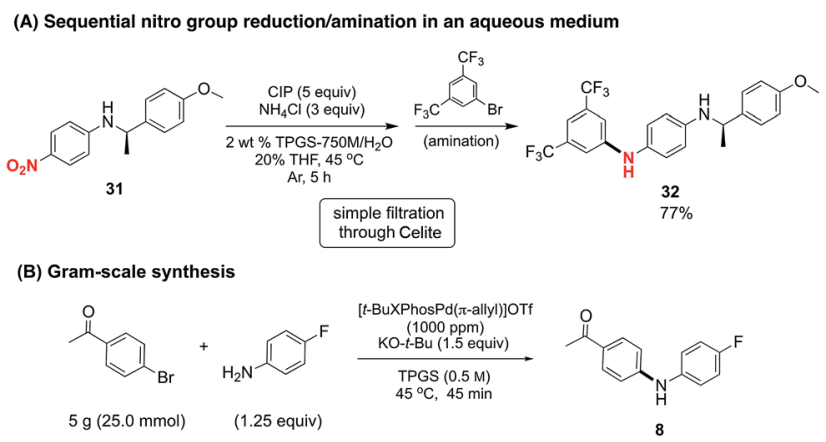

$5.67 \mathrm{~g}, 99 \%$
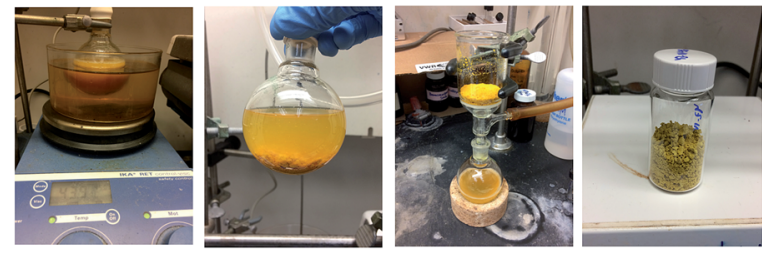

(C) Comparison study of an amination in water versus in organic solvent

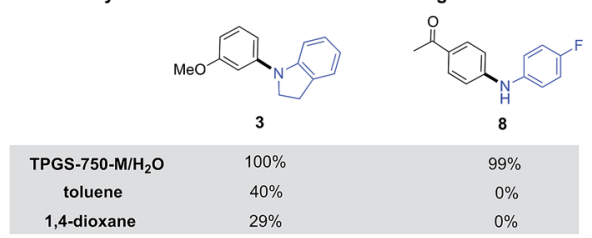

Scheme 3 (A) Sequential sustainable micellar catalysis leading to 32. (B) Gram scale synthesis of 8 in TPGS-750-M with easy product isolation. (C) Comparison study on the formation of 3 and 8 in TPGS$750-\mathrm{M}$ vs. in organic solvent. Conditions: $45^{\circ} \mathrm{C}, 1000 \mathrm{ppm}$ LPd catalyst loading, $0.5 \mathrm{M}, 16 \mathrm{~h}$. are often stable solids at ambient temperatures. Combining, therefore, a nitro group reduction followed (without isolation) by a ppm level Pd-catalyzed amination would expand the appeal of this methodology, especially for industrial applications. We have previously developed a nitro group reduction protocol using the same aqueous micellar medium, where commercially available and inexpensive carbonyl iron powder (CIP) has been shown to be amenable to scale-up, delivering grams of amination products. ${ }^{8 g}$ As illustrated in Scheme 3A, the crude amine product from the reduction of $\mathbf{3 1}$, following filtration through Celite, could be used directly in the amination protocol to afford the cross-coupling product 32 in good overall yield.

A gram-scale amination led to the preparation of diarylamine 8, starting with 4-fluoroaniline and 4-bromoacetophenone (Scheme 3B). The almost equally effective pre-catalyst $[t$ BuXPhos(Pd- $\pi$-allyl)]OTf (C8) ${ }^{14}$ was used due to its commercial availability. Without alteration from our optimized conditions (vide supra), the reaction run at 100 times its original scale was complete in less than one hour. More than five grams of pure product could be collected via filtration, with an astonishingly low $E$ factor $(<1)$, as a measure of waste created (see ESI $\dagger$ for details). ${ }^{15}$

While the synthesis of $\mathbf{8}$ was highly efficient at the ppm level of catalyst under aqueous conditions, such was not the case

(A) Influence of catalyst loading and temperature

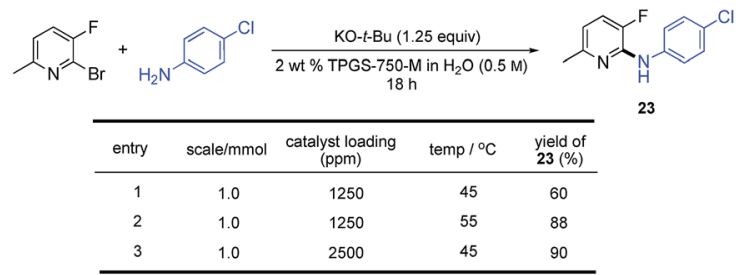

(B) Residual Pd in products

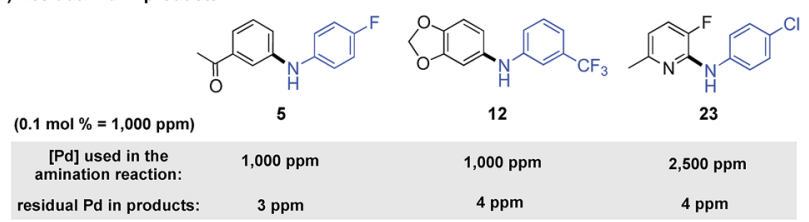

(C) Recycle study

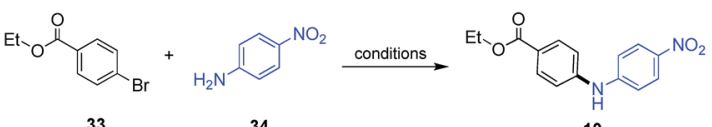

33

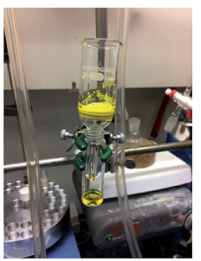

conditions: 34 (69 mg, $0.5 \mathrm{mmol}), 33(100 \mu \mathrm{L}, 0.625 \mathrm{mmol}), \mathrm{KOH}$ $(14 \mathrm{mg}, 0.25 \mathrm{mmol}), \mathrm{K}_{3} \mathrm{PO}_{4}(81 \mathrm{mg}, 0.35 \mathrm{mmol}) 1000 / 500 \mathrm{ppm}[t$ BuXPhosPd(cinnamyl)]OTf, $23^{\circ} \mathrm{C}, 20 \mathrm{~h}$ (see ESI for details).

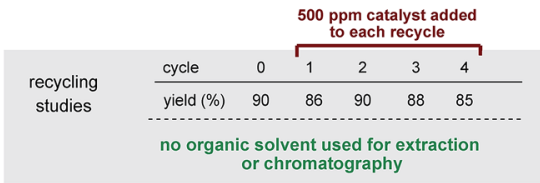

Scheme 4 (A) Influence of reaction scale, catalyst loading and temperature on micellar amination (B) ICP analysis of residual $\mathrm{Pd}$ detected in compounds prepared by ppm LPd micellar catalysis. (C) Recycle study of Buchwald-Hartwig amination at rt (see ESI† for details). 
when performed in organic solvents commonly used for these aminations. $^{4 e}$ Thus, in either toluene or 1,4-dioxane under otherwise identical conditions, none of the desired product was detected (Scheme 3C). NMR analyses showed a combination of the corresponding imine had formed, along with unreacted bromoacetophenone in ca. a 1:1 ratio. A similar solvent comparison study was performed leading to amine 3 , although low yields were obtained in this case as well. In the composite, these observations highlight the potentially significant (e.g., chemoselectivity) differences that can be found between traditional and micellar catalysis.

Although increasing the loading (e.g., from 0.10 to $0.25 \mathrm{~mol} \%$; see Scheme 2) for especially difficult C-N coupling reactions leads to formation of the desired amination, the same net outcome could be obtained using 1250 ppm Pd simply by a $10{ }^{\circ} \mathrm{C}$ increase in reaction temperature. Comparison studies leading to product $\mathbf{2 3}$ clearly showed that this was indeed the case (Scheme 4A).

By virtue of the ppm level of Pd catalyst associated with these aminations, the amount of residual metal to be found in the product amines, after standard workup and purification, is expected to be below the FDA-approved level of 10 ppm per dose. ${ }^{\mathbf{1 6}}$ As test cases, products (e.g., 5, 12, and 23; Scheme 4B) were randomly selected and subjected to ICP-MS analyses for Pd content. Results (see ESI $\dagger$ for details) indicated that each has a Pd content $\leq 4 \mathrm{ppm}$, suggesting that additional time and cost

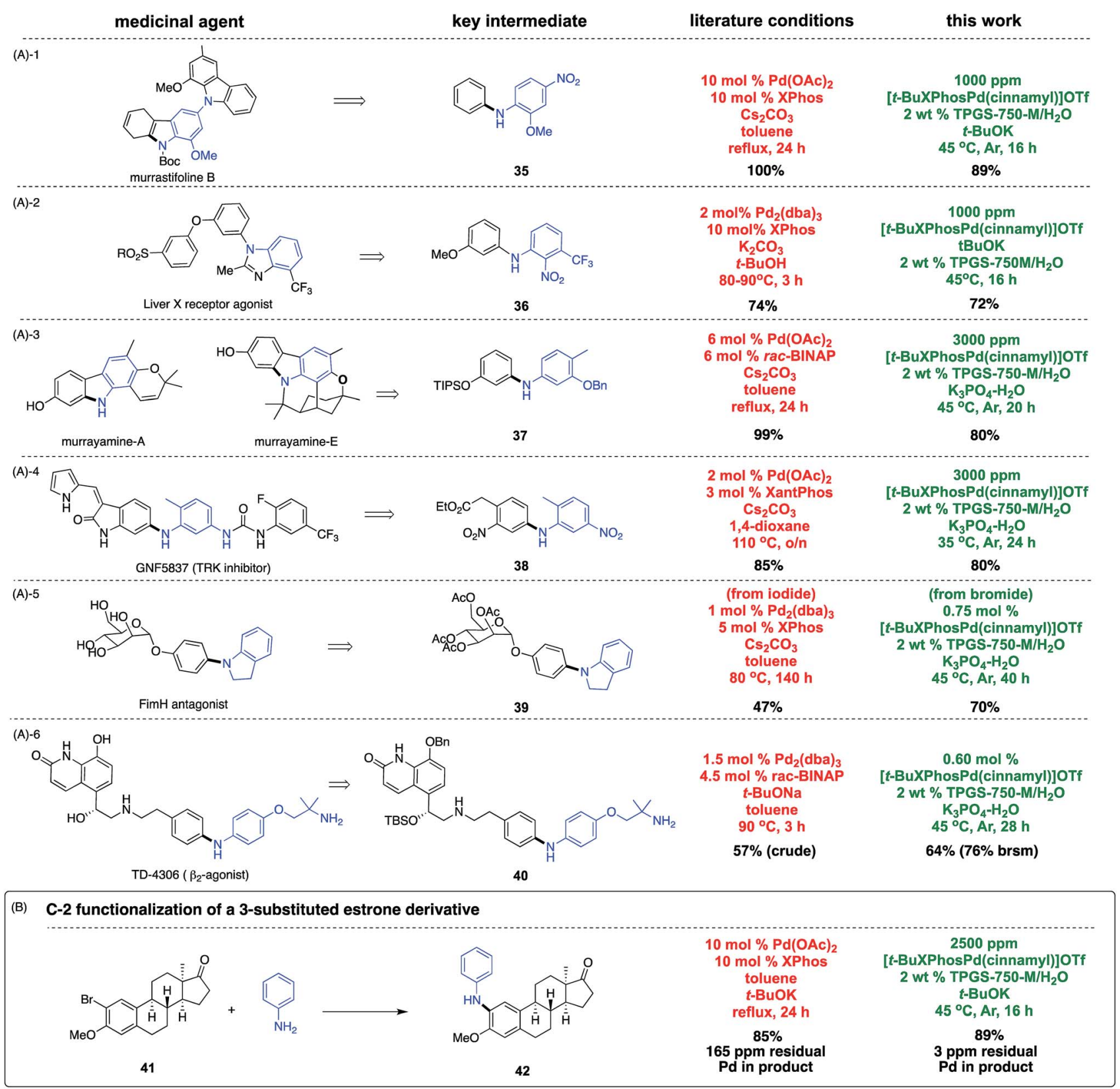

Scheme 5 (A) Direct comparisons between literature conditions and those using ppm level Pd catalysis in water. (B) Comparison with recent amination of an estrone derivative. Yields refer to isolated material. 
associated with further purification, contrary to that based on traditional couplings done at 10-100 times the loading of Pd, should not be needed for products formed using this technology. Further reduction in the amount of Pd invested can be achieved by recycling of the aqueous reaction medium. As shown in the coupling between ethyl $p$-bromobenzoate (33) and $p$-nitroaniline (34; Scheme 4C), the solid diarylamine product 35 is isolated by simple gravity filtration. The filtrate is then reused as the reaction medium after supplementing with 500 ppm of ligated Pd. As summarized in this scheme, amine $\mathbf{3 5}$ is formed in good yields consistently over four additional cycles, with an average input of only 600 ppm (i.e., $0.06 \mathrm{~mol} \%$ ) of catalyst $\mathbf{C 1 0}$ per coupling.

To document the applicability of this aqueous coupling chemistry, direct comparisons were made by focusing on six key intermediates associated with medicinally relevant natural products or APIs (Scheme 5A). ${ }^{17}$ Aminations that arrive at key intermediates 35-40 reveal that this methodology operates at much lower catalyst loadings and temperatures, and is typically faster than reactions in organic media. Moreover, yields tend to be comparable to, or better than, those reported previously. Another recent example providing further testimony to the potential savings of precious metal is shown in Scheme $5 \mathrm{~B}^{18}$ Amination at C-2 in a 3-substituted estrone derivative afforded product 42 using 40 times less palladium and ligand $(10 \mathrm{~mol} \%$ $=100000 \mathrm{ppm})$, run at a lower temperature $\left(45\right.$ vs. $\left.110^{\circ} \mathrm{C}\right)$, and in less time (16 vs. $24 \mathrm{~h}$ ). The level of residual Pd in the product from both approaches led to the expected outcomes: from amination in toluene: $165 \mathrm{ppm} \mathrm{Pd}$, while from this ppm level amination in water: 3 ppm Pd.

\section{Conclusions}

Overall, this work provides a significant advance in Pd-catalyzed C-N cross-coupling chemistry. Specifically, it offers the synthetic community, based on a known and well defined $1: 1 \mathrm{Pd}: \mathrm{L}$ complex, aminations that: (1) rely on ppm levels of palladium; (2) are glove-box-free and operationally simple; (3) are general, highly efficient, and offer gram-scale capability; (4) perform under very mild conditions, with temperatures at $45{ }^{\circ} \mathrm{C}$ or below; (5) utilize an aqueous reaction medium that avoids organic solvents, yet involve very little water; (6) allow for recycling of the surfactant, water, and catalyst; and (7) lead to ppm levels of residual palladium in the amination products. The process further illustrates the synthetic potential of pre-complexing a lipophilic ligand with Pd that can lead to pre-catalyst loadings at the ppm level. Extending the current technology to additional $\mathrm{C}-\mathrm{N}$ cross couplings as well as use of Fe/ppm Pd nanoparticles ${ }^{8 a}$ for similar synthetic purposes are currently under study.

\section{Conflicts of interest}

There are no conflicts to declare.

\section{Acknowledgements}

Financial support provided by Novartis and the NSF (GOALI 1566212) is warmly acknowledged. The palladium used in this study was generously supplied by Dr Thomas Colacot, formerly at Johnson Matthey. Y. Z. would like to express thanks to Prof. David M. Chenoweth for the inspiring mentoring in the past.

\section{Notes and references}

1 (a) A. DeAngelis and T. J. Colacot, in New Trends in CrossCoupling: Theory and Applications, The Royal Society of Chemistry, London, 2015, pp. 20-90; (b) C. C. C. Johansson Seechurn, H. Li and T. J. Colacot, in New Trends in CrossCoupling: Theory and Applications, The Royal Society of Chemistry, London, 2015, pp. 91-138; (c) Q. Yao, E. P. Kinney and C. Zheng, Org. Lett., 2004, 6, 2997; (d) N. T. S. Phan, M. Van Der Sluys and C. W. Jones, Adv. Synth. Catal., 2006, 348, 609.

2 (a) T. J. Colacot, Platinum Met. Rev., 2011, 55, 84; (b) C. C. C. Johansson Seechurn, M. O. Kitching, T. J. Colacot and V. Snieckus, Angew. Chem. Int. Ed., 2012, 51, 5062; Angew. Chem., 2012, 124, 5150; (c) G. Molander, J. P. Wolfe and M. Lerhed, Science of synthesis: cross-coupling and Hecktype reactions, Thieme, Stuttgart, Workbench edn, 2013; (d) P. G. Gildner and T. J. Colacot, Organometallics, 2015, 34, 5497.

3 (a) B. Schlummer and U. Scholz, Adv. Synth. Catal., 2004, 346, 1599; (b) J.-P. Corbet and G. Mignani, Chem. Rev., 2006, 106, 2651; (c) C. Torborg and M. Beller, Adv. Synth. Catal., 2009, 351, 3027; (d) M. M. Heravi, Z. Kheilkordi, V. Zadsirjan, M. Heydari and M. J. Malmir, Organomet. Chem., 2018, 861, 17.

4 (a) J. F. Hartwig, Nature, 2008, 455, 314; (b) D. S. Surry and S. L. Buchwald, Chem. Sci., 2011, 2, 27; (c) R. J. Lundgren and M. Stradiotto, Chem.-Eur. J., 2012, 18, 9758; (d) J. Bariwal and E. Van der Eycken, Chem. Soc. Rev., 2013, 42, 9283; (e) P. Ruiz-Castillo and S. L. Buchwald, Chem. Rev., 2016, 116, 12564.

5 (a) J. P. Wolfe, S. Wagaw, J.-F. Marcoux and S. L. Buchwald, Acc. Chem. Res., 1998, 31, 805; (b) J. F. Hartwig, Angew. Chem., Int. Ed., 1998, 37, 2046; (c) E. A. B. Kantchev, C. J. O'Brien and M. G. Organ, Angew. Chem., Int. Ed., 2007, 46, 2768; Angew. Chem., 2007, 119, 2824; (d) D. S. Surry and S. L. Buchwald, Angew. Chem., Int. Ed., 2008, 47, 6338; Angew. Chem., 2008, 120, 6438; (e) S. Díez-González, N. Marion and S. P. Nolan, Chem. Rev., 2009, 109, 3612; $(f)$ C. A. Fleckenstein and H. Plenio, Chem. Soc. Rev., 2010, 39, 694; $(g)$ G. C. Fortman and S. P. Nolan, Chem. Soc. Rev., 2011, 40, 5151; (h) B. J. Tardiff, R. McDonald, M. J. Ferguson and M. Stradiotto, J. Org. Chem., 2012, 77, 1056; ( $i$ ) S. M. Crawford, C. B. Lavery and M. Stradiotto, Chem.-Eur. J., 2013, 19, 16760; (j) M. Su, N. Hoshiya and S. L. Buchwald, Org. Lett., 2014, 16, 832; $(k)$ F. Inoue, M. Kashihara, M. R. Yadav and Y. Nakao, Angew. Chem. Int. Ed., 2017, 56, 13307; Angew. Chem., 2017, 129, 13492; (l) J. Richardson, J. C. Ruble, E. A. Love and S. Berritt, J. Org. Chem., 2017, 82, 3741; $(m)$ X.-B. Lan, Y. Li, Y.-F. Li, D.-S. Shen, Z. Ke and F.-S. Liu, J. Org. Chem., 2017, 82, 2914; (n) J. Mao, J. Zhang, S. Zhang and P. J. Walsh, Dalton Trans., 2018, 47, 8690; (o) J. M. Dennis, N. A. White, 
R. Y. Liu and S. L. Buchwald, J. Am. Chem. Soc., 2018, 140, 4721. For a (phosphine or NHC) ligandless, intramolecular approach, see T.-S. Mei, X. Wang and J.-Q. Yu, J. Am. Chem. Soc., 2009, 131, 10806.

6 (a) D. Zim and S. L. Buchwald, Org. Lett., 2003, 5, 2413; (b) N. Marion and S. P. Nolan, Acc. Chem. Res., 2008, 41, 1440; (c) N. R. Biscoe, B. P. Fors and S. L. Buchwald, J. Am. Chem. Soc., 2008, 130, 6686; (d) C. C. C. Johansson Seechurn, S. L. Parisel and T. J. Colacot, J. Org. Chem., 2011, 76, 7918; (e) C. Valente, M. Pompeo, M. Sayah and M. G. Organ, Org. Process Res. Dev., 2014, 18, 180; $(f)$ A. J. DeAngelis, P. G. Gildner, R. Chow and T. J. Colacot, J. Org. Chem., 2015, 80, 6794.

7 (a) J. F. Hartwig, Acc. Chem. Res., 2008, 41, 1534; (b) N. C. Bruno, M. T. Tudge and S. L. Buchwald, Chem. Sci., 2013, 4, 916; (c) N. C. Bruno and S. L. Buchwald, Org. Lett., 2013, 15, 2876; (d) N. C. Bruno, N. Niljianskul and S. L. Buchwald, J. Org. Chem., 2014, 79, 4161; (e) For a review, see A. Bruneau, M. Roche, M. Alami and S. Messaoudi, ACS Catal., 2015, 5, 1386.

8 For prior studies on sustainable metal-catalyzed transformations by us, see (a) S. Handa, Y. Wang, F. Gallou and B. H. Lipshutz, Science, 2015, 349, 1087; (b) S. Handa, M. P. Andersson, F. Gallou, J. Reilly and B. H. Lipshutz, Angew. Chem. Int. Ed., 2016, 55, 4914; Angew. Chem., 2016, 128, 4998; (c) J. Feng, S. Handa, F. Gallou and B. H. Lipshutz, Angew. Chem. Int. Ed., 2016, 55, 8979; Angew. Chem., 2016, 128, 9125; (d) C. M. Gabriel, M. Parmentier, C. Riegert, M. Lanz, S. Handa, B. H. Lipshutz and F. Gallou, Org. Process Res. Dev., 2017, 21, 247; (e) S. Handa, J. D. Smith, M. S. Hageman, M. Gonzalez and B. H. Lipshutz, ACS Catal., 2016, 6, 8179; (f) P. Klumphu, C. Desfeux, Y. Zhang, S. Handa, F. Gallou and B. H. Lipshutz, Chem. Sci., 2017, 8, 6354; $(g)$ N. R. Lee, A. A. Bikovtseva, M. Cortes-Clerget, F. Gallou and B. H. Lipshutz, Org. Lett., 2018, 19, 6518; (h) S. Handa, J. B. Smith, Y. Zhang, T. Balaram, F. Gallou and B. H. Lipshutz, Org. Lett., 2018, 20, 542.

9 (a) B. H. Lipshutz, D. W. Chung and B. Rich, Adv. Synth. Catal., 2009, 351, 1717; (b) B. J. Tardiff and M. Stadiotto, Eur. J. Org. Chem., 2012, 21, 3972; (c) N. A. Isley, S. Dobarco and B. H. Lipshutz, Green Chem., 2014, 16, 1480; (d) C. Salomé, P. Wagner, M. Bollenbach, F. Bihel, J.-J. Bourguignon and M. Schmitt, Tetrahedron, 2014, 70, 3413; (e) P. Wagner, M. Bollenbach, C. Doebelin, F. Bihel, J.-J. Bourguignon, C. Salomé and M. Schmitt, Green Chem., 2014, 16, 4170.

10 (a) E. Davies and R. Renner, Chem. World, 2011, 1, 50; (b) P. Mike, New Sci., 2011, 2, 2799.

11 See $(a)$ H. Li, C. C. C. J. Seechurn and T. J. Colacot, ACS Catal., 2012, 2, 1147 and references therein; (b) C. Amatore, G. Broeker, A. Jutland and F. Khalil, J. Am. Chem. Soc., 1997, 119, 5176; (c) I. J. S. Fairlamb, A. R. Kapdi and A. F. Lee, Org. Lett., 2004, 6, 4435; (d) C. S. Wei, G. H. M. Davies, O. Soltani, J. Albrecht, Q. Gao,
C. Pathirana, Y. Hsiao, S. Tummala and M. D. Eastgate, Angew. Chem., Int. Ed., 2013, 52, 5822.

12 (a) P. S. Kutchukian, J. F. Dropinski, K. D. Dykstra, B. Li, D. A. DiRocco, E. C. Streckfuss, L.-C. Campeau, T. Cernak, P. Vachal, I. W. Davies, S. W. Krska and S. D. Dreher, Chem. Sci., 2016, 7, 2604; (b) M. R. Uehling, R. P. King, S. W. Krska, T. Cernak and S. L. Buchwald, Science, 2019, 363, 405.

13 Other compounds from the Merck informer library, such as X1 (Sigma catalog 901753), X14 (Sigma catalog 901749), and X17 (Sigma catalog 901753) failed to give the desired products of amination. Rather, the presence of readily hydrolysable functionality (e.g., esters, lactones, carbamates, etc.) present in each appeared to be the major side reactions. This was not unexpected in light of the recent work by Merck and co-workers that required preformed $\mathrm{Pd}(\mathrm{II})$ intermediates arrived at using stoichiometric levels of palladium; see ref. $12 b$.

$14[t$-BuXPhos(Pd- $\pi$-allyl) $]$ OTf is commercially available through Johnson Matthey (catalogue number: Pd-174). The other two analogues, $[t$-BuXPhos(Pd- $\pi$-crotyl $)]$ OTf and $[t$ BuXPhos(Pd- $\pi$-cinnamyl)]OTf can be prepared following a two-step sequence from ready available material, as described in ref. $6 f$.

15 Treatment of the waste water associated with use of aqueous TPGS-750-M has been fully addressed at Novartis, the procedure having been first disclosed at the recent Workshop on Chemistry in Water, UCSB June-July, 2019. This study was alluded to in an earlier report by the same group in Basel (i.e., Dr Fabrice Gallou); see F. Gallou, N. A. Isley, A. Ganic, U. Onken, M. Parmentier, Green Chem., 2016, 18, 14. Details will be disclosed in a forthcoming publication by Novartis.

16 F.D.A., Q3D Elemental Impurities Guidance for Industry, https:/www.fda.gov/downloads/drugs/guidances/ ucm371025.pdf.

17 (a) C. Börger, A. W. Schmidt and H.-J. Knölker, Synlett, 2014, 25, 1381; (b) J. M. Travins, R. C. Bernotas, D. H. Kaufman, E. Quinet, P. Nambi, I. Feingold, C. Huselton, A. Wilhelmsson, A. Goos-Nilsson and J. Wrobel, Bioorg. Med. Chem. Lett., 2010, 20, 526; (c) C. Schuster, K. K. Julich-Gruner, H. Schnitzler, R. Hesse, A. Jäger, A. W. Schmidt and H.-J. Knölker, J. Org. Chem., 2015, 80, 5666; (d) P. Albaugh, Y. Fan, Y. Mi, F. Sun, F. Adrian, N. Li, Y. Jia, Y. Sarkisova, A. Kreusch, T. Hood, M. Lu, G. Liu, S. Huang, Z. Liu, J. Loren, T. Tuntland, D. S. Karanewsky, H. M. Seidel and V. Molteni, ACS Med. Chem. Lett., 2012, 3, 140; (e) X. Jiang, D. Abgottspon, S. Kleeb, S. Rabbani, M. Scharenberg, M. Wittwer, M. Haug, O. Schwardt and B. Ernst, J. Med. Chem., 2012, 55, 4700; (f) R. M. McKinnell, U. Klein, M. S. Linsell, E. J. Moran, M. B. Nodwell, J. W. Pfeiffer, R. Thomas, C. Yu and J. R. Jacobsen, Bioorg. Med. Chem. Lett., 2014, 24, 2871.

18 I. Bacsa, D. Szemerédi, J. Wölfling, G. Schneider, L. Fekete and E. Mernyák, Beilstein J. Org. Chem., 2018, 14, 998. 